2.

\title{
Game Design Lineages
}

\author{
Minecraft's Inventory
}

Chris Bateman \& José P. Zagal

Transactions of the Digital G ames Research Association

April 2018, Vol 3 No 3, pp 13-46

ISSN 2328-9422

(C) The text of this work is licensed under a Creative Commons Attribution -- NonCommercial --NonDerivative 2.5 License (http://creativecommons.org/licenses/by-nc-nd/2.5/).

IMAGES: All images appearing in this work are property of the respective copyright owners, and are not released into the Creative Commons. The respective owners reserve all rights.

\section{ABSTRACT}

Game design is conditioned by the practice, both formal and informal, of drawing from previous designs as a source of knowledge and inspiration. Innovation in game design is thus often the result of old ideas recombined in novel ways. We propose the concept of the game design lineage as a framework for tracing, analyzing, understanding and explaining the historical significance of specific design elements in games. In addition to game design elements, a design lineage should consider a game's socio-cultural context, including the design and player practices of its creators, and the relationship between these and the prevailing player practices of the time. We contrast this with approaches 


\section{ToDiGRA}

that consider individual games as their unit of analysis - e.g. comparing different games with each other and establishing connections between them without considering the historical context of their player practices. We feel this approach, while insightful for understanding changes between games that are superficially similar, risks implying a strict Linnaean-style inheritance pattern (inheritance by genre), and thus struggles to account for games with a diversity of design elements that originate elsewhere. We argue that the flow of influences in game design is typically fluid and heterogeneous, and not constrained by genre. Key to this concept of a game design lineage is the role of player practices; i.e. how players receive, perceive and interact with games, and the ways these have shaped the ideas that are then implemented. We illustrate the game design lineage approach with an analysis of Minecraft's inventory system, tracing its different elements across multiple games, genres, designers, and player practices.

\section{Keywords}

Game design lineage, player practice, RPG, Minecraft, D\&D, Dungeon Master

\section{INTRODUCTION}

How can we articulate the knowledge of game designers? One wellestablished method has been to identify and abstract important design ideas, disentangle them from any specific game, and formulate them as a concept or schemata. The underlying assumption is that an abstract idea is more easily communicated and also more readily usable by others who can instantiate that concept in their games. These are approaches that tend to deconstruct games into their constituent elements e.g. as patterns (Björk \& Holopainen 2005), unit operations (Bogost 2006), or ludemes (Parlett 2015).

It can be productive to decompose otherwise complex systems into constituent components as a means of analysis. However, there are 
dangers in treating any such decomposed element as merely a building block or tool in the design toolbox. These approaches often isolate game design elements from the social, cultural, technological and other contexts in which they reside. This makes it harder to understand why certain elements may have been used, why they might have been popular, who they might have been popular with, and more besides.

Consider the use of passwords in 8-bit videogames, for example. Outside of the context of the arcade, which favored short, intense play experiences in order to facilitate coin drops, games on early home computers, or consoles such as the NES, began to offer larger worlds and thus longer play experiences. Players of these games needed to record their progress so that they weren't always starting from scratch. They needed a 'save game', but the hardware was not yet able to easily support this option. A design solution was developed that was hardware independent: the password. Upon completing a portion of a game, an alphanumeric password would be presented to the player that allowed them to start the game from that point when the password was entered during a later play session.

We argue that it is not possible to fully understand this design element without also considering the context in which it was developed. Technology to store player data was prohibitively expensive at the time (the economic context encouraged this interim solution), player perceptions and interests were drawn towards more involved game experiences that required many hours to complete (the design trend towards longer games made 'banking' progress necessary to maintain an acceptable player experience), and inputting alphanumeric codes in a game was a familiar player practice due to the existence of 'cheat codes' that were used to alter the way a game executed (the solution was similar to a practice that players accepted and were familiar with).

The combinations of design elements that constitute games are constrained and shaped in specific ways that go beyond their construction as systems. Human and cultural influences serve important 


\section{ToDiGRA}

roles in elucidating practical elements of design, and these are especially important when reconstructing the historical circumstances behind a design.

The challenge of trying to understand a design element through its historical context is not novel and has been tackled across design-related disciplines in a variety of ways. Keller et al. (2006) describe how industrial designers collect materials they use for reference, while Brown discusses competitive reviews in web design as a method that helps designers "find out how other people solved the same design problems" (Brown 2011 p. 255). Similarly, Clark and Pause (2012) argue for the importance of developing theory with which to design architecture through the analysis of precedents. In fact, the knowledge acquired from studying precedents is useful across a range of design tasks (Eilouti 2009) and is often captured via design cases (e.g. Lawson 2014; Boling 2010).

In the context of game studies and game design, we feel that little work has been done to explore how best to provide a rich and deep insight such that game design knowledge can be understood, communicated and possibly used without losing the essential relationships required to make sense of the games in question. We offer the notion of the game design lineage as a means to partially address this challenge by contextualizing game systems within the player practices that provided both the environment that guided their implementation, and the background of understanding against which the game was encountered by its original players.

A game design lineage is a rich description of the networks of connections between common designed elements (in keeping with the notion of decomposing into coherent units or patterns) that is situated within an understanding of the context that conditioned the original design decisions that led to them, understood in terms of player practices (Bateman 2016a, 2016b). This perspective is important, not only in terms of more accurately investigating the historical connectivity of games and 
their designs, but also because insights from the past remain useful in the future, and can explain problems that are currently misunderstood or taken for granted.

\section{GAME DESIGN LINEAGES}

Game designer, Raph Koster, argued that "the evolution of the modern video game can largely be explained in terms of topology. Each generation of game can be described by a relatively minute alteration of the play space." Furthermore, he claimed that "when we design games, we often start with a previous game and change just one element in it.” (Koster 2004 pp. 78-9) He notes that we can use this to understand relations between games and how to group them (Koster 2014). For instance, a game with the same rules, but differences in presentation can be called a 'reskin', changing a rule however leads to a 'variant'. We call a collection of variants a 'family'. And, if the family becomes large enough, we end up with a 'genre'. As a game designer, Koster is concerned with the design of new games, and his perspective offers a heuristic for game design innovation. Juul built on this idea by organizing 'matching tile' games chronologically by year of release and connecting them with directional arrows that indicated the possibility of inspiration or the probable perception by players that this was the case (Juul 2008). So, an arrow from Puzz Loop (1998) to Zuma (2004) meant that the latter was probably inspired by the former or that players would likely perceive that to be the case.

Suominen (2016) argues that these approaches are genealogical in that they seem beholden to biology and evolution: a game is presented as a root or source, and from it, like branches on a tree. Thus, we can reveal connections between games, influences, "and sources of inspiration of game designers.” (Suominen 2016)

This biological metaphor, while at times productive, can be misleading. When designing games, it is more often the case that elements of multiple games (and other media) serve as inspiration rather than a single 
earlier game. Few games have a singular 'ancestor' from which they descend (sequels are perhaps the clearest exception). Designers pick and choose from the buffet of options they are aware of. Following the biological analogy, game design is akin to selecting genes from the different genomes that are known, and, from these disparate genes, assembling a new creation. With apologies to Mary Shelley, games are like Frankenstinian, assembled from a mish-mash of parts and inspirations.

Our concern with genealogical approaches is that they prioritize the game as the unit of analysis. However, many of the historical and design influences in games have resulted from design elements having been borrowed from other games, oftentimes outside of genre conventions. Genealogies and other genre-based taxonomies are ill-equipped to provide insights into how first-person shooter games such as Battlefield 4's (EA DICE, 2013) progression system was influenced by tabletop role-playing games (Zagal \& Altizer 2014) or how quick-time events made their way from laser-disc games like Dragon's Lair (Cinematronics 1983) to 21st century third-person action games such as the God of War series (e.g. SCE Santa Monica Studio 2005), first-person shooter games such as the Call of Duty: Modern Warfare series (e.g. Infinity Ward 2009), and sports games like FIFA 2010 World Cup South Africa (EA Canada 2010).

This genealogical concern also applies to videogames with significant configuration options, and games that are treated by their developers as a service (with frequent updates and changes) rather than a product (e.g. Duncan 2016). Consider the customization options allowed in the multiplayer games of Halo 2 (Bungie 2004): arguably, these different modes could be studied as variants (Cheung \& Huang 2012). Similarly, the game of World of Warcraft (Blizzard 2004) that was played when it was released has changed significantly, in terms of its game design, compared to what is played today. How can we best articulate what happens to these games in different players' hands and over time? 
Our answer to these challenges is the game design lineage. We present this as a research method that entails both historical research and careful game analysis. Since this is a first attempt at a game design lineage, it should not be taken as prescriptive of method but indicative - our goal is to show how to draw together the decompositional method of considering game elements that are a part of a game (rather than whole games) with the compositional method of positioning games within genres and genealogies. We focus on three contexts: (1) the player practices within which the game was both designed and first played; (2) the material constraints (both technological and economic) affecting the game; and (3) the creator vision, that synthesized these in a particular manner.

The method of constructing game design lineages, we propose, should not be taken to present definitive histories, if indeed such a thing is possible. While establishing causal relationships is beneficial to a design lineage, it should not be taken as a goal of the method. The purpose of a design lineage is not to prove that one situation led to a later situation, but to illuminate the latter situation in the light of the earlier ones that either hypothetically, anecdotally or evidentially provides a relevant context. In this regard, they resemble 'thick descriptions' of game design from anthropology i.e. descriptions that explain not just a behavior but also the context of that behavior such that even someone not belonging to the relevant culture can understand it (Geertz 1973).

\section{Player Practices}

Player practices are the habits that players have learned from playing games:

“...a 'player practice' is anything that a player has learned to do consistently. This includes, for instance, using the right stick on a controller to move the camera object, pressing a button to jump, smashing boxes to look for power-ups, and imagining that moving an animated 'doll' in a depicted space entails 'entering' the implied fictional world.” (Bateman, 2016a) 


\section{ToDiGRA}

It is precisely because player practices are habits - and community habits at that - that they are important to constructing a historical perspective on the design of specific games. Constructing a game design lineage necessarily means taking into account what player assumptions might have been and how they may have shaped the incorporation of specific design elements. In tracking interface practices for example, it is possible to draw partial conclusions from default control schemes as to the prevailing player practices within a particular development culture, or player community (Gkikas et al. 2007).

Player practices can be identified by observation or interrogation of players. When neither is available the design of games can be examined to produce hypothetical player practice claims. In this regard, we see no bar to individual players drawing on their own anecdotal experiences as evidence, although anecdotal observations of multiple players ought to be given more weight than purely personal observations.

It is important to recognize that player practices are not automatically reproduced. Designers often draw from existing player practices (e.g. the use of the right control stick of a joypad to control a camera object), while also actively subverting prevailing practices to innovate or meet their own play needs (e.g. Halo's abandonment of a multiple weapon inventory for a two-weapon system with streamlined controls and new design choices).

Below are a few questions that can guide the exploration of the player practices context:

- How was this design element related to contemporaneous player practices?

- In what ways was this design element familiar to players?

- How does the design element address a problem related to player practices?

- How was this design element received by players? 


\section{Material Constraints}

The technological affordances and limitations that existed when a design element was developed constitute a major part of the material constraints working upon any particular game. This includes the platform (i.e. the hardware and software frameworks that support other programs) and other relevant technologies, e.g. display equipment, input devices, and internet connectivity. Commercial considerations also form an important aspect of the material constraints. For example, the design of arcade games was conditioned by the material constraint of its business model, namely individual coin drops, a situation revolutionized by Gauntlet (Atari Games 1985), which accepted multiple coin drops in a single game - an early example of the ‘microtransaction' business model.

Bogost and Montfort's platform studies (2007) are salient examples of considering the relationship, including mutual influences, that the underlying hardware and software can have with games and their designed elements. Their book on the Atari 2600 demonstrates how technological constraints can influence and affect game design (Montfort \& Bogost 2009). It is important to consider both the constraints and affordances - what a given technology makes possible - since new technologies (both hardware, e.g. graphics chips, and software, e.g. game engines) have created novel avenues for design and discovery.

Questions for exploring the material constraints of design elements:

- How did this design element make use of existing technologies or tools?

- In what ways does the underlying technology support the design element?

- What technologies were necessary and how common were they?

- What commercial considerations affected the choices behind this design? 


\section{Creator Vision}

Examining this context requires an understanding of how a creator takes their existing habits, practices, and 'materials', and alters them in some way to create something new: their context, in other words. This may include exploring, when known, what games they might have played or been influenced by. It may also be necessary to consider other games produced by the same individual or studio. Since design practices are habits, the culture of design practice at specific companies become important. Thus Bethesda's commitment to drawing from the practices and experiences of tabletop role-playing games (Ramsay 2012) becomes part of the background of understanding for any of their computer roleplaying games in a way that is less significant for, say, Square-Enix, which has no such vision. Similarly, we can learn about the creators' context by examining game design and development artifacts beyond the games, including the code, comments within the code (Sample 2013), game design documents, manuals and more besides.

Questions for exploring the context of creator vision:

- What games might the creator know and have been influenced by?

- What tendencies do the creators demonstrate through prior or subsequent work?

- What do we know about the developer's design process or creative vision?

- What design trends were in vogue when this design element was developed?

\section{CHALLENGES IN CONSTRUCTING GAME DESIGN LINEAGES}

Because this research method can never be exhaustively complete, it presents substantial challenges. The main risk is the creation of deterministic narratives that are overly simplistic and reductionist. All 
explanatory narratives run this risk. Since one of the purposes of a game design lineage is to identify connections between design elements spanning games and time, there is danger in believing that because a connection exists, such influence was inevitable (rather than merely fortuitous).

There are also practical challenges. The three distinct contexts articulated above will, in practice, interrelate in various ways that may not be easy to disentangle. For instance, game creators often have their own player practices that influence their work and will deviate in various ways from the community practices, particularly when developers have access to cutting-edge technology. Creator vision and material constraints combine to shape player practices, just as player practices shape visions and drive the development of new technologies, providing new material constraints.

Consider the example of Quake's control schemes (id Software 1996). This is the point of origin for the mouselook control mechanism that led to the two-handed FPS control scheme, but it occurs only as an option in this game. Its standard control scheme uses arrow keys for movement, a player practice that was well established in the dungeon crawl games that descended from Dungeons \& Dragons (TSR 1974), of which Dungeon Master (FTL 1987) is a prominent example. Earlier id games such as Wolfenstein 3D (id Software 1992) and DOOM (id Software 1993) had conserved the player practice of using cursor keys for navigation, and were in effect dungeon crawlers in all but setting and pace. Notably, id's earlier Catacomb 3-D (id Software 1991) is expressly a dungeon crawler. In this example, a player practice associated with one style of game (arrow key controls with dungeon crawlers) develops into a new player practice associated with a different kind of game (mouselook with FPS games) with influence from material constraints (a new game engine) and creator vision (the faster paced gun play of the FPS).

Since it is hard to know beforehand what role a particular context may have had in shaping a game design element, this approach may seem 


\section{ToDiGRA}

daunting. It is also possible that important information may not have been known or available, and there are also frequent inconsistencies, even amongst those that were directly involved in the development of a feature or idea. This means that, in creating a game design lineage, it is often necessary to make assumptions based on incomplete or inexistent information when demonstrating the provenance of a certain game design element is strictly limited by the available sources.

We argue that, challenges notwithstanding, this is a fruitful method. It is also increasingly easier to access the information required for this kind of work. We have seen a rise of literature on videogames, both new and old. Strategy guides often include designer's commentary, game designers are more vocal in the media now than ever before, player communities exist online in easily accessible places, streaming and media sharing offer insights into how players play etc. Game reviews are also a source - they illustrate player practices prevalent at the time of a game's release and highlight connections between games and their creators that might not otherwise be known (Zagal et al. 2009).

The remainder of the paper is concerned with providing an illustrative case study before concluding with a reflection on future directions for this kind of work. 


\section{CASE STUDY: MINECRAFT'S INVENTORY}

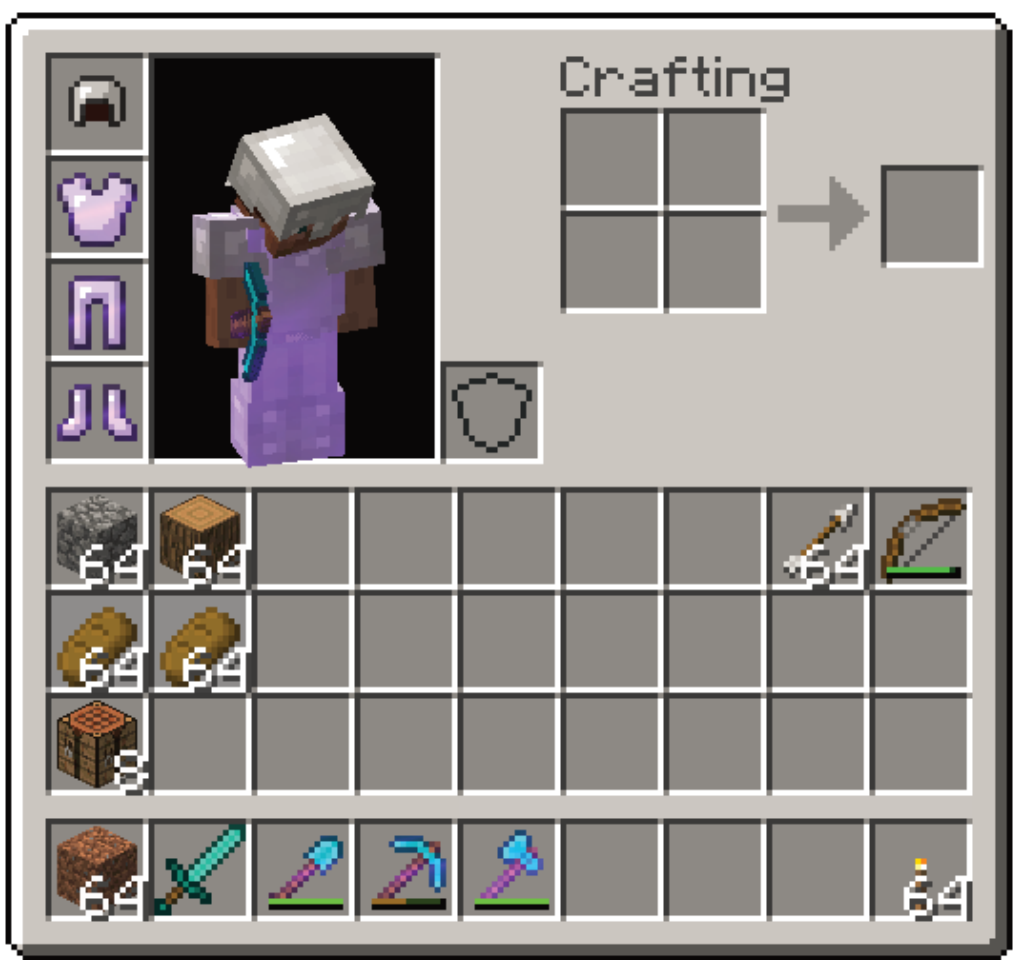

Figure 1: Minecraft Inventory System

Minecraft is arguably one of the most successful videogames of the 21st century. Its trajectory from a small independent game to a worldwide phenomenon earned its creators numerous industry accolades and significant financial success (Duncan 2011). In terms of its design, Minecraft was not significantly innovative - having been, in fact, described as a clone of an earlier game (Infiniminer) by its creator Markus “Notch” Persson (Goldberg \& Larsson 2015). That being said, Minecraft was significant in the way it utilized, recombined and reimagined game design elements from earlier games. 


\section{ToDiGRA}

In the following game design lineage we will discuss and analyze Minecraft's inventory system (Figure 1). What can immediately be seen are (1) a grid inventory, (2) a set of armor slots and an image of how they look upon the character, (3) a crafting area, and (4) a quickbar. We draw attention to the way that every single element of Minecraft's inventory descends directly from a lineage of videogames rooted at its base in the original tabletop role-playing game (RPG), Dungeons \& Dragons $(D \& D)$, the player practices of which are not overtly on display within Minecraft, but which can be shown to condition its design through the games that descended from its influence.

\section{Grid Inventories and the Paper Doll}

The grid inventory, prominent in Minecraft and the backbone of game inventories for years now, is part of a series of player practices that owe their origins to the influential Dungeon Master (FTL 1987). In all grid inventories, equipment is represented by a tile (often, but not exclusively square) showing an icon of the relevant item, and items are equipped by dragging these icons into the relevant spaces surrounding a figure representing the character. Items that are carried but not equipped are stored in rectangular blocks of empty squares. Every aspect of this design originates with Dungeon Master, which made a conscious break from the linear text inventories of earlier computer RPGs (Figure 2). 


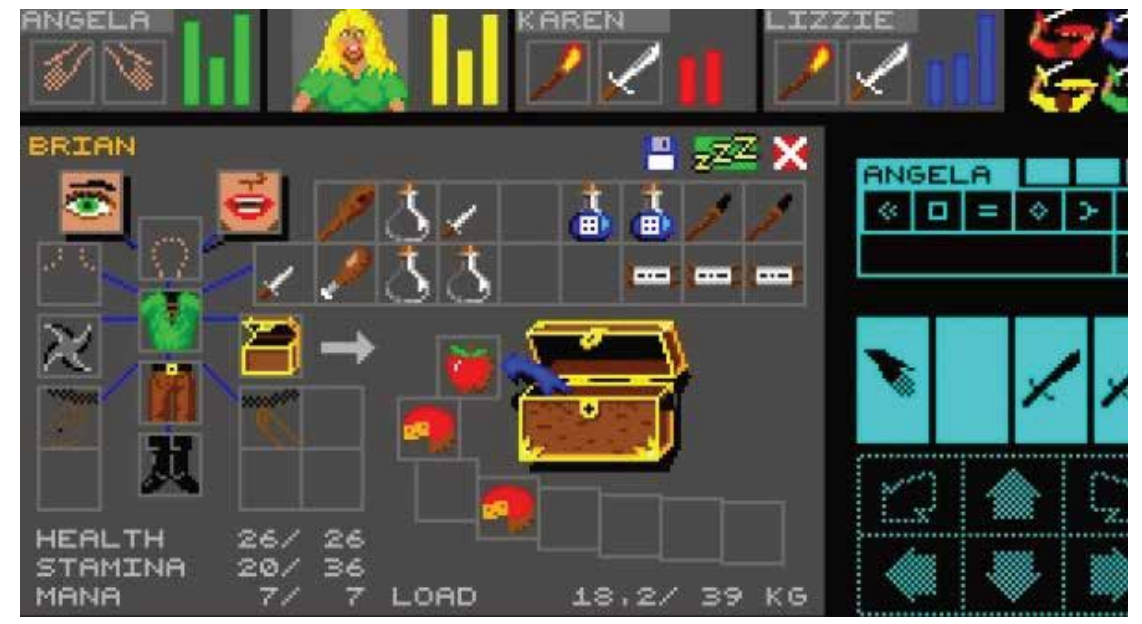

Figure 2 Inventory System in Dungeon Master

Dungeon Master came about through the co-operation of two designers who were intimately embedded in the player practices of tabletop roleplaying games and their early computer descendants - Doug Bell and Andy Jaros. SirTech's Wizardry (Sir-Tech 1980) had been their direct inspiration; they wanted to make a dungeon crawl in that vein, and set to work on what was then called Crystal Dragon. However, they didn't have the funds to complete the project alone (McFerran 2006). They ended up partnering with Wayne Holder, husband of fantasy and horror novelist Nancy Holder. The combination of a pair of designers rooted in the player practices of role playing games, a professional writer, and a business-savvy company owner was to prove immensely productive.

The core vision guiding the project was providing the player with a powerful sense of immersive presence. Jimmy Maher (2015), in a summary of the circumstances behind the game, characterizes their goal as “an embodied CRPG experience”, and quotes Nancy Holder as asking: “How do you go from being a player to being ‘in' a game?” Bell and Jaros, as game designers caught up in the well-established player practices of Wizardry and Dungeons \& Dragons, were repeatedly challenged by the Holders to push past the usual assumptions. As Wayne 
Holder later remarked, "At the time, most RPGs were adaptations of board games” and their ambition was to transcend this (Meston \& Arnold 1994 p. 131). Nancy Holder's experience as a horror writer informed the experiential design, while Wayne Holder's outsider perspective on role-playing helped remake the menu systems to bring them up to the standards then coming together in Graphical User Interfaces at the dawn of the WIMP (Windows/Icons/Menus/Pointer) era (Kovacs 1988).

Thus the creators' vision for Dungeon Master involved breaking down the sense of separation between the world and the character sheet, which earlier games in this lineage had inherited from $D \& D$. In Dungeon Master (named in reference to its tabletop progenitor), the player can find a sword on the floor of the rendered three-dimensional dungeon, move their pointer (styled as a hand) and grasp it, delivering it into slots in the grid inventory (Wayne Holder's WIMP-inspired innovation) or into the 'paper doll' slots representing each character's personal equipment. The widespread deployment of both these practices descend from this game, and they are conserved from this point, as Holder himself remarks (Meston \& Arnold 1994 p. 132): "We expected to be imitated... but it was amazing how many things we did that got completely borrowed." Indeed, comparing a screenshot of Minecraft's grid inventory with that of Dungeon Master's, the key difference is that Minecraft's appears shoddier in terms of presentation values.

\section{Crafting and Multi-Celled Inventories}

The process of manipulating game items in certain combinations to create new items has come to be termed 'crafting'. Minecraft's inventory screen has a box specifically for this purpose. Crafting formed no significant part of Dungeons \& Dragons player practices until the 3rd edition in 2000, and none of the notable early computer RPGs descending from it feature this concept. The means of creating magical items that tabletop $D \& D$ offered has had next to no influence, and while there are earlier examples of item-combinations such as Ultima IV's spell creation system (Garriott 1985) or Finders Keepers (Jones 
1985), it appears to be Diablo II (Blizzard North 2002) that largely establishes the design element and player practice of crafting through the introduction of the Horadric Cube, a secondary grid inventory of $3 \times 4$ spaces that includes a button to transmute its contents into a new magical item (Figure 3). This provided a means for players to create endgame items beyond waiting for them to drop, and although its function was considered fairly arcane at the time, it was nonetheless a central part of many players' experiences of this game.

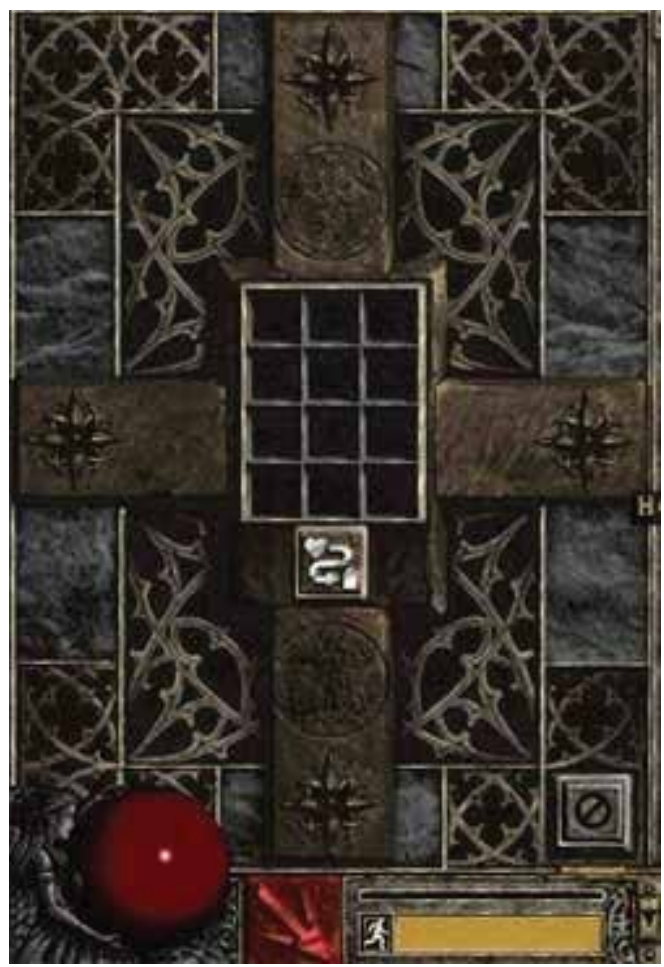

Figure 3 Diablo II's Horadric Cube (crafting system interface)

That the crafting box in Minecraft resembles that of the Horadric Cube is not coincidental: Diablo (Blizzard North 1996) and Diablo II were so commercially successful that it is these games (and the Elder Scrolls series, discussed below), that anchor the conservation of player practices 
in Western-style computer role-playing games from this point onward. The Japanese CRPG lineage, which also traces its heritage back to $D \& D$ via The Black Onyx (Rogers 1984) and Wizardry before it, would tell a different story, but one that does not bear on the game design lineage of Minecraft's inventory.

The original Diablo is one of the games that synthesize influences from both tabletop Dungeons \& Dragons, and its computer game inheritors. Co-creators Erich and Max Schaefer had played in the kind of mindless dungeon bash style of $D \& D$ that was common (but by no means universal) in the early days of the hobby:

"We wanted to do an RPG how we'd played Dungeons \& Dragons as kids: hit monsters and gain loot. Our mission was that we wanted the minimum amount of time between when you started the game up to when you were clubbing a skeleton.” (Edge 2010)

Indirect influences came in via the other co-creator, David Breivik, who had played Moria (Koeneke \& Todd 1983) and Angband (Cutler \& Astrand 1990), two early roguelike games descended ultimately from the unimaginatively titled dnd (Whisenhunt \& Wood 1975) on the PLATO educational computer network, work on which began the same year that tabletop $D \& D$ appeared. 


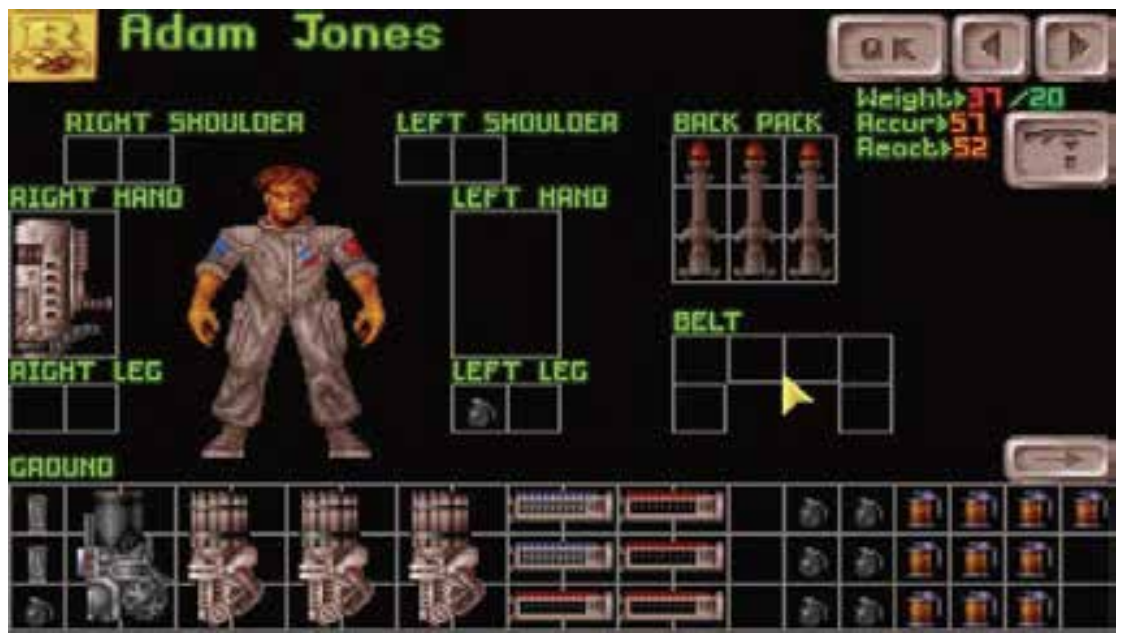

Figure 4 UFO Enemy Unknown

The inventory in Diablo has another key point of influence, however, namely Julian Gollop’s X-Com: UFO Defense (Gollop 1994), originally entitled UFO: Enemy Unknown. The influence here was in the idea of modifying the original grid inventory concept, which allocated one square to an item, by having items take up multiple spaces (Figure 4). In Diablo's inventory screen, weapons take up between three and six spaces in the grid, in various configurations, a design element and player practice established by and descending from $X$-Com, which all three of the Diablo creators mentioned above point to as their inspiration for the interface design (Edge 2010, Pitts 2006).

The multi-cell grid inventory, created by Gollop for $X$-Com, descends from a line of games the British programmer developed for 8-bit home computers. From the age of 14, Gollop was playing Dungeons \& Dragons and the strategy boardgames of Avalon Hill that had inspired it (Retro Gamer 2014). Gollop was influenced by the design of strategic boardgames, as can be seen with Rebelstar Raiders (Gollop 1984) and its sequels, although it is only with Laser Squad (Target Games 1988) that he began to combine $D \& D$-style differential characters - and thus inventories - with the player practices he had developed across his 
Rebelstar games, the last of which had been released earlier in the same year. The multi-cell grid inventory arguably has its origin at the tabletop, since Battlecars (Chalk \& Livingstone 1983), which Gollop adapted into a videogame, used a similar system, and this boardgame descended directly from Steve Jackson's classic tabletop autoduellist wargame Car Wars (Jackson 1981), for which allocating weaponry to the limited spaces available in the chassis was a major aspect of its play.

Another of Jackson's games, GURPS (Jackson 1986), serves as a more direct connection between crafting practices in videogames and their tabletop predecessors. While Diablo II appears to be the game with the most direct influence on Minecraft's crafting, it is important to recognize that the Elder Scrolls series is another contributor to the player practices that sustain crafting in games. Bethesda were deeply involved with the narrative practices of tabletop role-playing, and were far more interested in role play than the simple kill-and-level rule play that inspired Diablo. It is Daggerfall (Bethesda 1996) that marks the point that Bethesda's influences change from $D \& D$ to later tabletop role-playing systems, particularly GURPS (Gamespy 2001 as archived at RPGCodex.net).

A striking aspect of the inventory screen in Daggerfall is its division into categories like Weapons \& Armour, Magic Items, Clothing \& Misc, and Ingredients. As noted below, this was a common aspect of Dungeons \& Dragons character sheets, but it hadn't been used much in computer RPGs. The influence of tabletop practices is also felt in Bethesda's crafting systems. Arena (Bethesda 1994) had a spell creation system that was a modular version of D\&D's fixed-definition spells. Daggerfall, on the other hand, has a more detailed spell and weapon enchantment system, where players choose from a set of effects then modify casting cost and purchase price by altering chance of effect, duration, or magnitude. This draws very clearly from the GURPS concepts of Advantages and Disadvantages that would go on to influence Fallout (Interplay 1997). 
Tabletop RPGs hadn't had a motive to include crafting systems, but the emphasis on volumes of loot earned in computer RPGs (a product, in part, of much faster-paced play) created a need to find other things to do with items other than just sell them. For Daggerfall, the system that most resembles future crafting practices is the Potion Maker. Certain items in the game were characterized as Ingredients and could be combined in a Mixing Cauldron, accessed from Temples or the Assassins' Guild. Mixing could be done freely, or recipes (acquired as treasure drops) could be used to operate the Mixing Cauldron automatically.

Although the Mixing Cauldron's scope is narrower than Diablo II's Horadric Cube, both develop the same design element: one where the inventory is neither a source of equipment for immediate use (as in $D \& D$ ), or simply fodder for sale (e.g. most pre-90's CRPGs), but a set of active elements that can be combined in different patterns to get other equipment. Material constraints are relevant here, since these player practices made no sense at the tabletop, where complex look-up tables would be required. On computers, however, the availability of automated game systems kicked off experimentation with crafting as soon as there was sufficient memory space for such luxuries.

\section{Quickbars}

One final element of Minecraft's inventory remains unaccounted for: the bar at the bottom that allows rapid access to the contents of the inventory. This is an inventory practice that makes no sense at the tabletop, yet it will hardly be a surprise at this point to demonstrate that it too descends from a lineage tracing its departure point to $D \& D$. Here, the pivotal game is EverQuest (SOE 1999), which is the first of the 3D 'graphical MUDs' - later known as a Massively Multiplayer Role-playing Game (MMORPG).

The earliest MUDs, such as the ground-breaking MUD1 (Trubshaw \& Bartle 1978) were much more exercises in world building and community play than adaptations of $D \& D$, although Bartle notes that he 
had played the game (Bartle 2016). It is the LP MUDs (Pensjö 1989) and especially the DikuMUDs (Hammer et al. 1990), originating in Sweden and Denmark respectively, that saw in the MUDs the opportunity to (yet again) adapt $D \& D$ for computer form (Aarseth 1997 pp. 142-61), repeating what had happened back in 1974 on the PLATO educational network. From its first publication through to the early 1990s, wherever there was an opportunity to adapt the various player practices of $D \& D$ into a computerized form, it was taken.

The inventory systems of all these early online games remain resolutely in the style of the early text adventures, and thus in the form of $D \& D$ : a list of words. A text command 'inventory', often available as just 'i', would list all the items that the player was carrying as a simple linear list. Each item was specified in the design of the game, either as a unique object (in most adventure games) or as a class to be instanced (in computer RPGs and MUDs). As long as these games were represented in text, there was no possibility of it being otherwise.

The graphical interface of the MMORPG is the material constraint that gives rise to the quickbar. However, tracing the practices of MMOs, or indeed any game that is run as a service, requires significantly greater effort than investigating games released as products. Game-as-services means constant changes and updates, and this makes archaeology difficult to adequately perform. Nonetheless, we know of an early (perhaps the first) form of the hotbar in the original EverQuest. The player was able to customize its contents by placing different actions (at this point primarily described in words e.g. "Melee Attack") onto the bar, where it could be quickly clicked with the mouse, or activated with a hotkey. The name 'hotbar' is a reference to the concept of a 'hotkey', which has its origin in the graphical interfaces of computer operating systems. It appears to be EverQuest's early competitor, Dark Age of Camelot (Mythic Entertainment 2001), which coins the term 'quickbar' (styled in Minecraft's case as a 'quick-bar'), and as with all games of this style, the design varies radically throughout its life. The functionality, however, remained parallel to the equivalent practices of EverQuest. 
CRPGs were already moving towards this kind of customizable inventory practice, as the available hardware resources increased and games took advantage of this to add more functionality. The action bar at the bottom of the screen in the officially licensed $D \& D$ computer RPG Baldur's Gate (BioWare 1998) functions as a proto-quickbar, even though inventory items are a small part of the space allocated for it. Similarly, Diablo II offers a quickbar-like system that is presented as being part of the fictional world of the game by linking its functionality to belt items. Each belt provides the capacity to access potions, with different belts having varying capacities. However, by Diablo III (Blizzard Entertainment 2012), this experiment had merged with the main lineage of quickbar practices that had blossomed in the MMORPGs.

There is another potential link between the quickbar and MUDs worth considering. MUD players often found that there were actions (or clusters of actions) that they needed to perform frequently, and swiftly hit upon a solution via running additional software in parallel to the MUD that supported macros. A macro was a script of text actions coupled to a key press to trigger it, typically (but not exclusively) the function keys (F1-F12), which were ideally suited for such purposes. Later MUD client software began to build in these macro systems automatically, because the player practices had become dependent upon the macro concept for smooth play. Note also that it was the players who added this element to the MUDs, with no involvement from the game developers.

Because the developers of EverQuest were MUD players (Bartle 2003), they appear to have been drawn to providing customizable interface elements like the hotbar, thus accelerating the development of what would become called the quickbar: they were (on this reading) a graphical substitute for macros, a customizable element that could tailor to the individual player's practices. MUDs required more actions, in part because they brought together multiple players, which necessitated communication and performance which were irrelevant in a single player 
game. MMORPGs inherited this requirement, and developed the quickbar practices to deal with it. Here, in this final element of Minecraft's inventory design, is a clear example of why examining the history of games as player practices can reveal aspects that are invisible if they are examined solely as artefacts, since it is only through the actions of the players that the practices of games are sustained.

\section{The Origins of Game Inventories}

For almost twenty years after its original release, TSR's Dungeons \& Dragons was the wellspring from which many of the player practices and design elements of computer role-playing games were established and conserved. $D \& D$ had many influences from the tabletop scene preceding it, not least of which were the wargames of Charles S. Robert's Avalon Hill, but the sheer degree to which the $D \& D$ rules were distributed throughout the US (primarily via college players) - both by purchase and through unlicensed copies - made this the definitive version of tabletop RPG player practices that were conserved by the computer variants. All the way through the 70 s and 80 s, $D \& D$ was feeding its player practices directly or indirectly into computer games, as with the example above of the influence of early dungeon crawlers on the development of the FPS lineage.

In terms of inventories, Dungeons \& Dragons effectively invents them (although it did not coin this term) or rather, acquires this practice from early non-commercial tabletop role-playing games, and then becomes the locus of the conservation of player practices by being so widely distributed. The key to the inventory is the character sheet, which collected together all manner of fields (Name, Class, Attributes, Alignment and so forth) including a list of all items possessed - the prototype of the inventory. $D \& D$ 's original 1974 edition did not have a pre-designed character sheet, and players recorded all the text and numbers required to specify their characters without an established template. However, experimentation in home-printed character sheets soon appeared, such as the one created by Bob Rupport in 1975 (Peterson 
2013). TSR only established an official printed character record sheet in 1977. These early examples demonstrate that tabletop RPG inventories in the early days were quite frequently multiple written lists: Rupport's version divides the inventory into sections named Weapons/Armour, Magic Equipment, and Other Equipment, while TSR's official version provided separate boxes for Magic Items and Normal Items, stressing the importance of Magic Items (acquired as treasure) to character advancement, both in the tabletop game and in its immediate successors.

When early computer role-playing games took up these practices, there was little sense in maintaining the distinct segments, with Daggerfall a rare exception. It was the material qualities of paper and pencils, and the requirements for manual maintenance of lists in this form that had made separate boxes useful. The material constraints of computer games, however, all but dictated a single inventory system accessed with a unified control mechanism - as can be seen with Wizardry and The Bard's Tale (Interplay 1985).

In The Bard's Tale, each character in the party is allowed eight items in their inventory - a number that facilitated selecting items using a single press of the number keys (the material constraint that informed this design). Equipped items were marked with an asterisk, and although an image of party members is shown, the choices of items do not change that appearance (as they do in Minecraft). Despite being five years older, Wizardry's inventory is almost identical, the one difference being the use of a question mark to indicate items that had not been identified, a player practice invented by $D \& D$ but largely maintained only in Rogue (Toy \& Wichman 1980) and its descendants.

Michael Cranford, the game designer and programmer at Interplay who was responsible for almost every aspect of The Bard's Tale except its art, was not only playing Dungeons \& Dragons at the tabletop (frequently as Dungeon Master,) but also playing a great deal of Wizardry (Crooked Bee 2013). Just as with Bell and Jaros’ Dungeon Master, Cranford wanted to create a 'Wizardry Killer', and with The Bard's Tale achieved 
a streamlined perfection of the player practices of that earlier game, as well as bringing in a few of the new player practices TSR had added in Advanced Dungeons \& Dragons (Gygax 1978), such as changing classes - itself a contribution from the player community.

Recognizing Dungeons \& Dragons' role in initiating inventory design elements underlines the importance of considering player practices for game design lineages. The tabletop role-playing game had radically different material constraints to early computer games, and it was the desire to preserve the already established player practices that made the inventory systems for Wizardry and The Bard's Tale what they were and the desire to transcend what had gone before which made Dungeon Master such an influential title.

The design of every game is conditioned by the conservation of player practices, which sustains those practices that are effective in satisfying the visceral or imaginative needs of players. Every example here serves to elucidate this point, and to show how games are never isolated objects: they are always embedded in the manifold of player practices responsible for their creation, and which they then contribute to maintaining.

\section{CONCLUSIONS AND FUTURE DIRECTIONS}

The player is the heart of the game, and game design conserves player practices because designers are also players. We can trace lineages of design elements and their intimately related player practices, not because successful games are rare exceptions that borrow their practices from earlier games, but because games that borrow the majority of their practices from earlier games are best positioned to be successful especially if they bring something new to the table in the process. Notch may not have played tabletop Dungeons \& Dragons, or The Bard's Tale, or Dungeon Master, or X-Com, or EverQuest, but the inventory practices of Minecraft nonetheless inherit the successful variations that these games introduced upon a bedrock of established player practices. 
Understanding games and game design by examining player practices and constructing game design lineages does not entail any dramatic sea-change to the way games are made or studied, it merely involves foregrounding what is all too commonly dismissed: games are connected by historical lineages sustained by common player practices, which is to say, things the player learns to do consistently. The game designer, a player themselves, recreates the player practices learned from other games, as well as expanding and intentionally subverting them through the application of new creative visions, conditioned in part by the affordances offered by new material constraints. Even when a game designer thinks they are pulling together isolatable atomic elements of a game design, they may simply be ignoring the practices those elements belong to, and which are required to make sense of them. The game design lineage method invites both researchers and game designers to reconsider the role of history and culture in understanding games.

Not only do game design lineages represent a new research tool for understanding the history of games and the practices of game design, they potentially have significant relevance for commercial game development. Certain games succeeded commercially while others did not: the reasons for this are not always (perhaps, not ever) entirely reducible to the design decisions or the quality of implementation. Sometimes the prevailing player practices created difficulties within the marketplace because a certain game did not align with player expectations, while other games with apparently conservative designs (i.e. designs that did not innovate) enjoyed commercial success despite the frequent claims by players that they preferred originality (e.g. Schmalz 2015). We leave open the question of how these aspects of commercial success could be researched, or even whether definitive answers are available to researchers. Nonetheless, the preceding discussion makes a case for the influence of player practices and game design lineages upon the commercial success of Minecraft that, at the very least, offers a new perspective that commercial game designers and game studies scholars may want to seriously consider. 
40 ToDiGRA

\section{ACKNOWLEDGEMENTS}

With thanks to Richard Bartle, Richard Boon, Erlend Grefsrud, Dan Griliopoulos, Jacob Hartmann, Doug Hill, Jacobo Luengo, Yik-Sian Seow, Oscar Strik and Samantha Vega. Parts of this paper appeared in five posts on http://blog.ihobo.com starting here: http://blog.ihobo.com/ 2016/09/index.html.

\section{BIBLIOGRAPHY}

Aarseth, E. (1997). Cybertext: Perspectives on Ergodic Literature. Baltimore: Johns Hopkins University Press.

Atari Games. (1985). Gauntlet. Milpitas, CA: Atari Games.

Bartle, R. (2003). Designing Virtual Worlds., 1st edition. New Riders Games.

—_. (2016). 'Personal Communication'.

Bateman, C. (2016a). 'No-one Plays Alone'. Presented at the First International Joint Conference of DiGRA and FDG 2016, Dundee, Scotland.

_ (2016b). 'The Lineages of Play', Journal of Playwork Practice, 3/ 2: 95-106.

Bethesda. (1994). The Elder Scrolls Arena. Rockville, MD: Bethesda Softworks.

—_. (1996). Daggerfall. Rockville, MD: Bethesda Softworks.

BioWare. (1998). Baldur's Gate. Irvine, CA: Interplay Entertainment.

Björk, S., \& Holopainen, J. (2005). Patterns in Game Design. Game Development Series. Hingham, Massachusetts: Charles River Media Inc. 
Blizzard. (2004). World of Warcraft. Irvine, CA: Blizzard Entertainment.

Blizzard Entertainment. (2012). Diablo III. Irvine, CA: Blizzard Entertainment.

Blizzard North. (1996). Diablo. Irvine, CA: Blizzard Entertainment.

—. (2002). Diablo II. Irvine, CA: Blizzard Entertainment.

Bogost, I., \& Montfort, N. (2007). 'New Media as Material Constraint: An Introduction to Platform Studies’. Presented at the 1st International HASTAC Conference, April 19.

Bogost, Ian. (2006). Unit Operations: An Approach to Videogame Criticism. Cambridge: MIT Press.

Boling, E. (2010). 'The Need for Design Cases: Disseminating Design Knowledge', International Journal of Designs for Learning, 1/1: 1-8.

Brown, D. (2011). Communicating Design 2nd Edition. Berkeley, CA: New Riders.

Bungie. (2004). Halo 2. Redmond, WA: Microsoft Game Studios.

Chalk, G., \& Livingstone, I. (1983). Battlecars. Nottingham, UK: Games Workshop.

Cheung, G., \& Huang, J. (2012). 'Remix and Play: Lessons from Rule Variants in Texas Hold'em and Halo 2'. Proceedings of the ACM 2012 conference on Computer Supported Cooperative Work, pp. 559-68. Presented at the CSCW'12, Seattle, WA: ACM.

Cinematronics. (1983). Dragon’s Lair. El Cajon, CA: Cinematronics.

Clark, R. H., \& Pause, M. (2012). Precedents in Architecture, 4th Edition. Hoboken, NJ: John Wiley \& Sons, Inc. 
42 ToDiGRA

Crooked Bee. (2013). 'RPG Codex Retrospective Interview: Michael Cranford on Bard's Tale, Interplay, and Centauri Alliance'. RPG Codex. Retrieved February 14, 2017, from <http://www.rpgcodex.net/ content.php?id=9163>

Cutler, A., \& Astrand, A. (1990). Angband.

Duncan, S. C. (2011). 'Minecraft, Beyond Construction and Survival', Well Played, 1/1: 1-22.

—. (2016). 'Mandatory Upgrades: The Evolving Mechanics and Theme of Android Netrunner', Analog Game Studies, 3/5.

EA Canada. (2010). 302 FIFA World Cup South Africa. Redwood City, CA: EA Sports.

Edge. (2010). ‘The Making of... Diablo’, Edge Magazine, 210: 104-7.

Eilouti, B. H. (2009). 'Design knowledge recycling using precedentbased analysis and synthesis models', Design Studies, 30/4: 340-68. DOI: 10.1016/j.destud.2009.03.001

FTL. (1987). Dungeon Master. San Diego, CA: FTL Games.

Gamespy. (2001). 'Ted Peterson Interview'. Gamespy. Retrieved February 15, 2017, from <http://www.rpgcodex.net/forums/ index.php?threads/im-looking-forward-to-oblivion.9614/ page-4\#post-151132>

Garriott, R. (1985). Ultima IV: Quest of the Avatar. Austin, TX: Origin Systems.

Geertz, C. (1973). 'Thick Description: Toward Interpretive Theory of Culture'. Geertz C. (ed.) The Interpretation of Cultures: Selected Essays, pp. 37-59. Basic Books: New York. 
Gkikas, K., Nathanael, D., \& Marmaras, N. (2007). 'The evolution of FPS games controllers: how use progressively shaped their present design'. Presented at the Panhellenic Conference on Informatics.

Goldberg, D., \& Larsson, L. (2015). Minecraft, Second Edition: The Unlikely Tale of Markus 'Notch' Persson and the Game that Changed Everything. Seven Stories Press.

Gollop, J. (1984). Rebelstar Raiders. London: Red Shift.

—. (1994). X-Com: UFO Defense. Alameda, CA: MicroProse.

Gygax, G. (1978). Advanced Dungeons \& Dragons Player's Handbook. Lake Geneva:WI: TSR Hobbies Inc.

Hammer, S., Seifert, M., Stærfeldt, H. H., Madsen, T., \& Nyboe, K. (1990). DikuMUD.

id Software. (1991). Catacomb 3-D. Shreveport, LA: Softdisk.

—_. (1992). Wolfenstein 3D. Garland, TX: Apogee Software.

— (1993). Doom. Mesquite:TX: id Software.

—_. (1996). Quake. New York, NY: GT Interactive.

Infinity Ward. (2009). Call of Duty: Modern Warfare 2. Santa Monica, CA: Activision.

Interplay. (1985). Tales of the Unknown, Volume 1: The Bard's Tale. Redwood City, CA: Electronic Arts.

—_. (1997). Fallout. Irvine, CA: Interplay Entertainment.

Jackson, S. (1981). Car Wars. Austin, TX: Steve Jackson Games.

—_. (1986). GURPS. Austin, TX: Steve Jackson Games.

Jones, D. (1985). Finders Keepers. London: Mastertronic. 
44 ToDiGRA

Juul, J. (2008). 'Swap Adjacent Gems to Make Sets of Three: A History of Matching Tile Games’, Artifact, 2: 205-16.

Keller, A. I., Pasman, G. J., \& Stappers, P. J. (2006). 'Collections designers keep: collecting visual material for inspiration and reference', CoDesign, 2/1: 17-33.

Koeneke, R. A., \& Todd, J. W. (1983). Moria.

Koster, R. (2004). A Theory of Fun for Game Design. Paraglyph.

—. (2014). 'When is a Clone', Raph Koster's Website.

Kovacs, R. (1988). 'Interview of Wayne Holder’, ST-Report, 24.

Lawson, B. (2014). 'Schemata, gambits and precedent: Some factors in design expertise’, Design Studies, 25/5: 443-57.

Maher, J. (2015). 'Dungeon Master, Part 1: The Making of'. The Digital Antiquarian. Retrieved February 14, 2017, from <http:/www.filfre.net/ 2015/12/dungeon-master-part-1-the-making-of/>

McFerran, D. (2006). 'The Making of Dungeon Master', Retro Gamer Magazine, 34: 30-1.

Meston, Z., \& Arnold, J. D. (1994). 'An Interview with Wayne Holder'. Dungeon Master II: The Official Strategy Guide, pp. 131-3. Sandwich Islands Publishing: Lahaina, HI.

Montfort, N., \& Bogost, I. (2009). Racing the Beam: The Atari Video Computer System. Platform Studies. Boston, MA: MIT Press.

Mythic Entertainment. (2001). Dark Age of Camelot. Los Angeles, CA: Vivendi Games.

Parlett, D. (2015). 'What's a Ludeme? - and who really invented it?', The Incompleat Gamester. 
Pensjö, L. (1989). LPMud.

Peterson, J. (2013). 'Character Sheets in 1975'. Playing at the World. Retrieved February 14, 2017, from $<$ http://playingattheworld.blogspot.co.uk/2013/07/character-sheetsin-1975.html >

Pitts, R. (2006). 'Secret Sauce: The Rise of Blizzard'. The Escapist, no. 48, Retrieved 28th February 2017, from $<$ http://www.escapistmagazine.com/articles/view/video-games/issues/ issue_48/289-Secret-Sauce-The-Rise-of-Blizzard.3>

Ramsay, M. (2012). 'Christopher Weaver: Founder, Bethesda Softworks'. Gamers at Work: Stories Behind the Games People Play. Apress: New York, NY.

Retro Gamer. (2014). 'Julian Gollop’. Retro Gamer. Retrieved February 15, 2017, from <http://www.retrogamer.net/profiles/developer/juliangollop/>

Rogers, H. (1984). The Black Onyx (ザ・ブラックオニキス). Yokohama: Bullet-Proof Software.

Sample, M. (2013). 'Criminal Code: Procedural Logic and Rhetorical Excess in Videogames’, Digital Humanities Quarterly, 7/1.

SCE Santa Monica Studio. (2005). God of War. San Mateo, CA: Sony Computer Entertainment.

Schmalz, M. (2015). Limitation to Innovation in the North American Console Video Game Industry 2001-2013: A Critical Analysis. Dissertation, The University of Western Ontarion. https://ir.lib.uwo.ca/ etd/3393

Sir-Tech. (1980). Wizardry: Proving Grounds of the Mad Overlord. New York, NY: Sir-Tech Software. 
46 ToDiGRA

SOE. (1999). Everquest. San Diego, CA: Sony Online Entertainment.

Suominen, J. (2016). 'How to Present the History of Digital Games', Games and Culture.

Target Games. (1988). Laser Squad. London, England: Blade Software.

Toy, M., \& Wichman, G. (1980). Rogue.

Trubshaw, R., \& Bartle, R. (1978). MUD1.

TSR. (1974). Dungeons \& Dragons. Lake Geneva:WI: Tactical Studies Rules.

Whisenhunt, G., \& Wood, R. (1975). dnd (PLATO system).

Zagal, José P., \& Altizer, R. (2014). 'Examining "RPG Elements": Systems of Character Progression'. Proceedings of the 9th International Conference on the Foundations of Digital Games. Presented at the Foundations of Digital Games (FDG) 2014, Society for the Advancement of the Science of Digital Games.

Zagal, Jose P., Ladd, A., \& Johnson, T. (2009). 'Characterizing and Understanding Game Reviews'. 4th International Conference on the Foundations of Digital Games. Orlando, FL: ACM. 